\title{
Pediatri Hemşirelerinin Terapötik Oyuna Yönelik Bilgi, Görüş ve Uygulamaları
}

\author{
Ramazan İnci'® ${ }^{1}$, Ulviye Günay² ${ }^{2}$
}

'Batman Üniversitesi Sağlık Yüksek Okulu Hemşirelik Bölümü, Batman, Türkiye

2̇nönü Üniversitesi Hemşirelik Fakültesi, Çocuk Sağlığı ve Hastalıkları Hemşireliği Anabilim Dalı, Malatya, Türkiye

Ramazan İnci, Arş. Gör. Ulviye Günay, Dr. Öğr. Üyesi

Bu makale ikinci yazar tarafından yürütülen aynı isimli yüksek lisans tezinden üretilmişti

İletişim:

Dr. Öğr. Üyesi Ulviye Günay

İnönü Üniversitesi Hemşirelik Fakültesi, Çocuk

Sağlığı ve Hastalıkları Hemşireliği Anabilim

Dalı, Malatya, Türkiye

Tel: +905066914390

E-Posta: ulviye.gunay@inonu.edu.tr

\section{ÖZET}

Amaç: Bu araştırma pediatri hemşirelerinin terapötik oyuna yönelik bilgi, görüş ve uygulamalarını belirlemek amacıyla yapıldı.

Hastalar ve Yöntem: Bu çalışma tanımlayıcı tipte, Aralık 2016-Mayıs 2017 tarihleri arasında Malatya, Diyarbakır ve Batman'da bulunan dört hastanenin pediatri kliniklerinde çalışan 126 hemşire ile yapıldı. Veriler; hemşireler için tanıtıc bilgi formu ve hemşireler için terapötik oyun bilgi, görüş ve uygulama değerlendirme formu ile toplandı. Verilerin değerlendirilmesinde yüzdelik, frekans, aritmetik ortalama ve standart sapma testleri kullanıldı.

Bulgular: Hemşirelerin \%64.2'sinin terapötik oyunu; hemşire ile çocuk arasında iletişimi sağlayan bir oyun türü olduğunu; \%83.3'ü çocuğun hastanede anksiyetesini azaltmak için uyguladığını, \%53.1'i çocuğa tıbbi oyuncakla işlemi anlatma, \%56.1'i hastane ile ilgili resim çizdirme yöntemlerini bildikleri saptandı. Hemşirelerin \%90,2'si çocuğun hastanede işlemlere uyumunu sağlamak için korkmaması gerektiğini söylediğini, \%59.5'nin fazla sayıda hasta olduğu için terapötik oyunu ara sıra uyguladıkları saptandı.

Sonuç: Pediatri hemşirelerinin terapötik oyun yöntemleri hakkında yeterli düzeyde bilgi sahibi oldukları ancak uygulamalarda yeterince kullanmadıkları belirlendi.

Anahtar sözcükler: Terapötik oyun, hastanede yatan çocuk, hemşire, görüş ve uygulamalar

\section{KNOWLEDGE, OPINIONS AND PRACTICES OF PEDIATRIC NURSES ABOUT THERAPEUTIC PLAY}

\section{ABSTRACT}

Purpose: The study was conducted to determine the knowledge, opinions and practices of pediatric nurses about therapeutic plays.

Patients and Methods: This descriptive study was carried out with 126 nurses working in pediatric clinics in four hospitals in the provinces of Malatya, Diyarbakır and Batman between December 2016 and May 2017. The data were collected using introductory information form for nurses and questionnaires for evaluating nurses' knowledge, opinions and practices about therapeutic plays. Percentiles, frequency, arithmetic mean and standard deviation tests were used in the evaluation of the data.

Results: It was determined that $64.2 \%$ of the nurses considered the therapeutic play as a type of game that enables communication between the nurses and children, $83.3 \%$ was found to apply therapeutic plays to reduce the anxiety of children in the hospital, $53.1 \%$ was found to know how to explain the procedure to the children with medical toys, and $56.1 \%$ was found to know the method of letting children draw hospital-related pictures. Of the nurses, $90.2 \%$ stated that the children should not be scared in order to ensure their compliance with the procedures in the hospital, and $59.5 \%$ was found to apply the therapeutic plays occasionally due to a great number of patients.

Conclusion: It was determined that pediatric nurses have an adequate knowledge about therapeutic play methods, but do not use them sufficiently in practice.

Keywords: Therapeutic play, hospitalized child, nurse, opinions and practices
Gönderilme Tarihi : 160cak 2018

Revizyon Tarihi : 19 Şubat 2018

Kabul Tarihi : 21 Şubat 2018 
$\mathrm{H}$ astalık ve hastanede yatma her yaş grubu çocuk ve ailesi için stresli, hoş olmayan bir durumdur (1). Çocuğa göre hastanede yatma genel olarak; aileden ayrılma, ürkütücü bir ortam, yabancı kişiler, ağrılı invaziv girişimler, okulundan ve arkadaşlarından ayrı kalma ve kısıtlanma anlamına gelebilmektedir $(1,2)$.

Pediatri hemşireleri çocuğun hastane ve hastanede yapılan işlemlere uyum sağlaması, duygularını ifade etmesi, stres ve kaygısını giderme, ağrısını azaltma ve baş etme becerilerini geliştirmede önemli sorumlulukları bulunmaktadır (1-3). Bu nedenle pediatri hemşirelerinin hastanede yatan çocuğa işbirliği ve uyum sağlayıc yöntemleri bilmesi, hemşirelik uygulamalarında bunlara yer vermesi gerekmektedir $(3,4)$. Hastanede yatan çocuğun fiziksel ve ruhsal olarak rahatlatılmasında farmakolojik yöntemler dışında farmakolojik olmayan çeşitli tamamlayıcı yöntemler kullanılmaktadır. Bunlar; sanat terapi, masaj, yoga, müzik dinletme, gevşeme egzersizleri ve oyun gibi yöntemlerdir (5).

Oyun bu tamamlayıcı yöntemlerden biri olarak, amaçlı ya da amaçsız, kurallı ya da kuralsız gerçekleştirilebilen, her durumda çocuğun isteyerek ve hoşlanarak katıldığı bir aktivitedir. Çocuğun fiziksel, bilişsel, duygusal, sosyal ve dil gelişiminde etkili olan oyun aynı zamanda çocuğun gerçek hayata hazırlanmasında önemli bir araçtır (6). Oyunun bir çeşidi olan "terapötik oyun" ise çocuğun benliğini rahatsız eden travmatik olaylarla ilgili deneyim ve korkularını oyun ve oyuncağa aktararak, problemle baş etme ve uyum sağlama becerisi geliş̧tirmesine yardımcı olan bir araçtır (1,7-9). Terapotik oyun, çocuğun hastanedeki bilmediği ağrılı ya da yoğun prosedürü öğrenmesi ve merakını gidermesini, işlemlerle ilgili duygularını ifade etmesini, böylece stres ve anksiyetesinin azaltmasını sağlar $(7,8)$. Bu oyun türü özel bir uzmanlık eğitimini gerektirmez, hastanede yatan çocuklar bir uzman gözetimi (oyun terapistti) olmadan rahatlıkla oynayabilir.

Terapötik oyun türleri arasında; dramatik oyun (çocuğa hastanede bulunan tıbbi oyuncaklar, kuklalar, maketler, steteskop, iğnesiz enjektörler vb. gibi araçlarla oynanmasına izin verilerek kendini ifade etmesini sağlama), yaratıcı oyun (resim çizdirme, cümle tamamlama, üç dilek testi vb.) ve enerji harcanarak oynanan oyunlar (yastığı yumruklama vb.) bulunmaktadır $(1,2,4,8)$.

Pediatri hemşireleri terapötik oyunu hastanede yatan çocuk için farklı durumlarda kullanabilirler. Bunlar: günlük rutin uygulamalar (çocuğun yaşam bulgularını ölçme, ilaç uygulamaları vb), cerrahi, ağrılı ve invaziv işlemler için çocuğun hazırlanmasında uygulayabilirler. Pediatri hemşirelerinin terapötik oyun yöntemlerini kullanabilmeleri için bilgili, becerili, sabırlı ve istekli olmaları gereklidir. Literatürde yapılan çalışmalarda terapötik oyun yönteminin çocuğun stres, ağrı ve anksiyete düzeyini azalttığı bildirilmektedir (5-9). Çin'de 7-12 yaşları arasında operasyon uygulanacak 107 çocukla yapılan randomize kontrollü bir araştırmada, deney grubunda yer alan 51 çocuğa hastaneye kabul prosedürü, anestezi ve izleme makineleri, yaşamsal bulguların ölçülmesi, oksijen verilmesi, intravenöz tedavi, nabız oksimetresi yerleştirilmesi gibi birçok uygulama oyuncaklar üzerinde tiyatro yöntemiyle bir saat süreyle açıklanmıştır. Ardından çocuklara soru sorma ve duygularını açıklama fırsatı verilmiştir. Konrol grubunda yer alan 57 çocuğa ise ameliyat öncesi rutin hazırlık yapılmış ve bilgi verilmiştir. Araştırma sonunda, deney grubunda yer alan çocukların kaygılarının, kontrol grubuna göre önemli bir şekilde azaldığı ve anestezi öncesinde daha az duygusal tepki verdikleri belirlenmiştir (10).

Pediatri hemşireliğinin bakım uygulamalarında önemli bir yere sahip olan terapötik oyun yönteminin ülkemizde pediatri hemşireleri tarafından ne ölçüde bilindiği ve hemşirelik uygulamalarında ne ölçüde yer verildiği bilinmemektedir.

\section{Araştırmanın amacı}

Bu çalışma, pediatri hemşirelerinin terapötik oyuna yönelik bilgi, görüş ve uygulamalarını belirlemek amacı ile yapıldı.

\section{Gereç ve yöntemler}

\section{Araştırmanın türü}

$\mathrm{Bu}$ araştırma, tanımlayıcı tipte, Doğu ve Güneydoğuda bulunan biri üniversite, diğerleri devlet hastanesi olmak üzere toplam 4 hastanenin çocuk kliniklerinde çalışan hemşirelerle Aralık 2016- Haziran 2017 tarihleri arasında yapıldı.

\section{Araştırmanın evren ve örneklemi}

Malatya (109), Diyarbakır (84), Batman (15) illerinin çocuk kliniklerinde çalışan toplam 208 pediatri hemşiresi araştırmanın evrenini oluşturdu. Evrenin tümünün araştırmaya alınması amaçlandığı için örneklem seçimine gidilmedi. Bu araştırmada, hemşirelerin 45'i çalışmaya katılmak istemediği, 27'si izinde olduğu, 10'u klinikte yeni çalışmaya başladığı için 126 hemşire çalışma kapsamına alındı.

\section{Araştırmaya alınma kriterleri}

- Çocuk kliniğinde en az bir yıl ve üzerinde çalışıyor olmak.

\section{Verilerin toplanması}

Veri toplama araçları

Verilerin toplanmasında, pediatri hemşirelerinin sosyo-demografik özelliklerini belirlemek için "Hemşire tanıtım formu" ve hemşirelerin terapötik oyuna yönelik bilgi, görüş ve uygulamalarını incelemek üzere araştırmacılar tarafından literatür doğrultusunda geliştirilen "pediatri hemşirelerinin terapötik oyuna yönelik bilgi, görüş ve uygulama değerlendirme anket formu" kullanıldı.

\section{Hemşire tanıtım anket formu}

Pediatri hemşirelerinin yaş, cinsiyet, medeni durum, eğitim durumu, gelir düzeyi, mesleki çalışma süresi ve pediatri kliniğine 
çalışma süresi gibi demografik özelliklerine yönelik soruların yer aldığı form 9 sorudan oluşmaktadır.

Pediatri hemşirelerinin terapötik oyuna yönelik bilgi, görüş ve uygulama değerlendirme anket formu.

Pediatri hemşirelerinin teropötik oyuna yönelik bilgi, görüş ve uygulamalarını değerlendirmek amacı ile araştırmacılar tarafından geliştirilen anket formu; terapötik oyuna yönelik bilgilerin değerlendirildiği 5, uygulamaların değerlendirildiği 10, görüşlerin değerlendirildiği 2 soru ile toplam 17 soru yer almaktadır (1-4).

Anket formu birinci araştırmacı tarafından hemşirelerle yüz yüze görüşme yöntemi ile dolduruldu. Her bir görüşme ortalama 15 dakika sürdü.

\section{Verilerin analizi}

Veriler bilgisayar ortamında değerlendirildi. Verilerin değerlendirilmesinde aritmetik ortalama, frekans, standart sapma ve yüzdelik testi kullanıldı.

\section{Araştırmanın etik yönü}

Araştırmaya başlamadan önce gerekli kurum izinleri alındı. Daha sonra İnönü Üniversitesi Bilimsel Araştırma ve Yayın Etiği Kurulundan etik onay alındı.

Araştırma kapsamına alınması planlanan pediatri hemşirelerine araştırmanın amacı ve gönüllülük esasına yönelik bilgi verildi. Daha sonra araştırmaya katılmak isteyen hemşirelerden sözlü ve yazılı izin alındı.

\section{Bulgular}

Çalışmaya katılan hemşirelerinin yaş ortalaması 30.89 \pm 7.18 , \%82.5'inin kadın, \%68.3'ünün lisans mezunu ve \%57.9'unun beş yıl ya da daha az süredir pediatri kliniğinde çalıştığı belirlendi. Pediatri hemşirelerinin \%54.7'sinin haftada 48 saat ve üzerinde, \%73.8'inin nöbet usulü çalıştığı, \%51.5'inin nöbette bakım verdiği hasta sayısının 11-20 arasında değiştiği saptandı (Tablo 1).

Hemşirelerin \%64.2'sinin terapötik oyunu; hemşire ile çocuk arasında iletişimi sağlayan bir oyun türü olduğunu; \%83.3'ü çocuğun hastanedeki anksiyetesini azaltmak için uyguladığını, \%84.1'i terapötik oyunun, çocuğu rahatlattığını ve sakinleştirdiğini belirtti (Tablo 2).

Terapötik oyun türleri ile ilgili hemşirelerin \%53.1'i çocuğa tıbbi oyuncakla işlemi anlatma, \%56.1'i hastane ile ilgili resim çizdirme yöntemlerini bildikleri saptandı. Hemşirelerin \%94.4'ü terapötik oyunun, hastane yatan tüm çocuklarla oynanabileceğini ifade ettikleri belirlendi (Tablo 2).

Pediatri hemşirelerinin $\% 77.7$ 'si hastanede yatan çocuklara terapötik oyun oynattığını, $\% 72.5$ 'i terapötik oyunu aşırı anksiyete ve korkusu olan çocuklara oynattığını belirtti. Hemşirelerin
Tablo 1. Pediatri hemşirelerinin tanıtıcı özelikleri $(\mathrm{N}=126)$

\begin{tabular}{|c|c|c|}
\hline Hemşirelerin çalıştığı hastaneler & Sayı & $\%$ \\
\hline $\begin{array}{l}\text { Turgut Özal Tıp Merkezi } \\
\text { Malatya Eğitim ve Araştırma Hastanesi } \\
\text { Diyarbakır Çocuk Hastanesi } \\
\text { Batman Kadın Doğum Çocuk Hastanesi }\end{array}$ & $\begin{array}{l}34 \\
20 \\
56 \\
16\end{array}$ & $\begin{array}{l}27.0 \\
15.9 \\
44.4 \\
12.7\end{array}$ \\
\hline $\begin{array}{l}\text { Hemşirelerin çalıştığı klinikler } \\
\text { Büyük Çocuk Kliniği } \\
\text { Süt Çocuğu Kliniği } \\
\text { Çocuk Dahiliye Kliniği } \\
\text { Çocuk Cerrahi Kliniği }\end{array}$ & $\begin{array}{l}37 \\
50 \\
22 \\
17\end{array}$ & $\begin{array}{l}29.4 \\
39.6 \\
17.5 \\
13.5\end{array}$ \\
\hline $\begin{array}{l}\text { Cinsiyet } \\
\text { Erkek } \\
\text { Kadın }\end{array}$ & $\begin{array}{c}22 \\
104 \\
\end{array}$ & $\begin{array}{l}17.5 \\
82.5 \\
\end{array}$ \\
\hline $\begin{array}{l}\text { Yaşı (yıl) } \\
20-25 \\
25-40 \\
41 \geq\end{array}$ & $\begin{array}{c}26 \\
91 \\
9\end{array}$ & $\begin{array}{l}20.6 \\
72.2 \\
7.14\end{array}$ \\
\hline $\begin{array}{l}\text { Öğrenim düzeyi } \\
\text { Lise } \\
\text { Ön lisans } \\
\text { Lisans } \\
\text { Lisansüstü } \\
\end{array}$ & $\begin{array}{c}8 \\
25 \\
86 \\
7\end{array}$ & $\begin{array}{c}6.3 \\
19.8 \\
68.3 \\
5.6\end{array}$ \\
\hline $\begin{array}{l}\text { Medeni durum } \\
\text { Evli } \\
\text { Bekar }\end{array}$ & $\begin{array}{l}84 \\
42 \\
\end{array}$ & $\begin{array}{l}66.7 \\
33.3 \\
\end{array}$ \\
\hline $\begin{array}{l}\text { Pediatri kliniğinde çalışma süresi } \\
2-5 \text { yıl } \\
6-10 \text { yıl } \\
11 \text { yıl ve üstü }\end{array}$ & $\begin{array}{l}73 \\
27 \\
26\end{array}$ & $\begin{array}{l}57.9 \\
21.4 \\
20.6\end{array}$ \\
\hline $\begin{array}{l}\text { Klinikte haftalık çalışma süresi } \\
40 \text { - } 48 \text { saat } \\
48 \text { saat ve üstü }\end{array}$ & $\begin{array}{l}57 \\
69\end{array}$ & $\begin{array}{l}45.2 \\
54.7 \\
\end{array}$ \\
\hline $\begin{array}{l}\text { Çalışma biçimi } \\
\text { Gündüz } \\
\text { Vardiya } \\
\text { Nöbet Usulü }\end{array}$ & $\begin{array}{l}15 \\
18 \\
93\end{array}$ & $\begin{array}{l}11.9 \\
14.3 \\
73.8\end{array}$ \\
\hline $\begin{array}{l}\text { Hemşire başına düşen hasta sayısı } \\
10 \text { ya da daha az hasta } \\
11-20 \text { hasta } \\
21 \text { ve üstü hasta }\end{array}$ & $\begin{array}{l}41 \\
65 \\
20\end{array}$ & $\begin{array}{l}32.5 \\
51.5 \\
15.8\end{array}$ \\
\hline
\end{tabular}

\%50.7'si çocuğun işlemlere uyumunu sağlamak için aile üyelerinin yanında bulunmasına izin verdiği saptandı. Hemşirelerin \%90,2'si çocuğun hastanede işlemlere uyumunu sağlamak için korkmaması gerektiğini söylediği belirlenirken, \%50.7'si klinikte en çok uygulanan terapötik oyunun, resim çizdirme olduğunu belitti. Hemşirelerin \%79.4'ü ara sıra, \%4.8'i gerektiğinde her zaman terapötik oyun oynattığını, ara sıra terapötik oyun oynatan hemşirelerin \%59.5'i sürekli oynatmama nedenini; hasta sayısının fazla olması şeklinde ifade ettiler (Tablo 3).

\section{Tartışma}

$\mathrm{Bu}$ araştırmada pediatri hemşirelerinin çoğunluğu terapötik oyunu; hemşire-çocuk arasında etkili iletişimi sağladığı, çocuğun anksiyetesini azaltma ve duygularını açıklamasını sağlamak amacı ile uygulandığını belirttiler. Hemşirelerin 
Tablo 2. Pediatri hemşirelerinin terapötik oyuna yönelik bilgi ve görüşlerinin dağılımı $(\mathrm{N}=126)$

\begin{tabular}{|c|c|c|}
\hline Bilgi Durumu & Sayı & $\%$ \\
\hline \multicolumn{3}{|l|}{ Hemşirelere göre terapötik oyunun tanımı } \\
\hline Hemşire - çocuk arasında iletişimi sağlayan bir çeşit oyun & 81 & 64.2 \\
\hline Zaman geçirme yöntemi & 15 & 11.8 \\
\hline laștıran bir işlem & 51 & 40.4 \\
\hline Klinikte ç & 63 & 50 \\
\hline $\begin{array}{l}\text { Sağlık çalışanları ile çocukların iletişim sağlamaları için } \\
\text { geliştirilen oyun }\end{array}$ & 20 & 15.7 \\
\hline \multicolumn{3}{|l|}{ Terapötik oyunun amacı } \\
\hline Çocuğun hastanedeki anksiy & 105 & 83.3 \\
\hline $\begin{array}{l}\text { Çocuğun hastanede işlemlere yönelik duygularını } \\
\text { açıklamasını sağlamak }\end{array}$ & 103 & 81.7 \\
\hline lini iyi hissetmesini sağlamak & 13 & 10.3 \\
\hline $\begin{array}{l}\text { Çocuğun olumlu baş etme yöntemleri geliştirmesini } \\
\text { sağlamak }\end{array}$ & 68 & 53.9 \\
\hline Çocuğun taburculuğunu hızlandırmak & 15 & 11.9 \\
\hline \multicolumn{3}{|l|}{ Oyunun hastanede yatan çocuk için yararı } \\
\hline & 106 & 84.1 \\
\hline & 98 & 62.8 \\
\hline setmesini sağlar & 61 & 48.4 \\
\hline rır & 44 & 34.9 \\
\hline & 26 & 20.6 \\
\hline Hastanede uygulanan işlemleri öğrenmesini & 75 & 59.4 \\
\hline \multicolumn{3}{|l|}{ Terapötik tekniklere yönelik bilgi durumu } \\
\hline Çocuğa üç dileğini sorma & 38 & 30.1 \\
\hline $\begin{array}{l}\text { Çocuğa en korktuğum şey, en sevdiğim gibi cümlelerle } \\
\text { duygularını öğrenme }\end{array}$ & 69 & 54.7 \\
\hline Çocuğa tıbbi oyuncakla işlemi anlatmak & 56 & 53.1 \\
\hline $\begin{array}{l}\text { Çocuğa hastane ile ilgili resim çizdirerek çizdiği şeyi } \\
\text { anlatmasını isteme }\end{array}$ & 58 & 56.1 \\
\hline Çocuğun duygularını yazması/ günlük tutması & 21 & 16.6 \\
\hline & 11 & 8.6 \\
\hline Uzman bir psikiyastrist eşliğinde çocuğa oyun oynatmak & 17 & 13.4 \\
\hline \multicolumn{3}{|l|}{ Terapötik oyun ne tür hastalığı olan çocuklar ile oynanır } \\
\hline & 37 & 29.6 \\
\hline & 31 & 24.6 \\
\hline & 18 & 14.2 \\
\hline Hastane yatan tüm çocuklarla & 121 & 94.4 \\
\hline \multicolumn{3}{|l|}{ Terapötik oyun hangi yaş gruplarına uygulanır } \\
\hline & 14 & 11.1 \\
\hline ubu & 39 & 30.9 \\
\hline rubu & 63 & 61.1 \\
\hline yaş grubu & 45 & 35.7 \\
\hline $12-18 y$ & 17 & 13.4 \\
\hline Yeni doğan dışında tüm & 55 & 43.6 \\
\hline
\end{tabular}

Hemşireler bir soruya birden fazla yanıt vermiş̧ir

çoğunluğu terapötik tekniklerini; tıbbi oyuncakla işlemi anlatma ve resim çizdirme yöntemlerini tanımladıkları ve hastanede yatan tüm yaş gruplarına uygulanabileceğini belirttiler.

Literatürde terapötik oyunun tanımı, amacı ve çeşitlerine yönelik hemşirelerin bilgi düzeyinin araştıııldığı bir çalışmaya rastlanmamıştır. Bununla birlikte yapılan çeşitli çalışmalarda terapötik oyunun çocukların duygularını açıklama ve kaygısını azaltmaya etkisi araştırılmıştır. Bunlardan Li et al, Hong Kong'da 7-12 yaşları arasında cerrahi operasyon uygulanacak 203 çocukla (97 deney, 106 kontrol grubu) yaptığı randomize kontrollü çalışmada, kontrol grubundaki çocuk ve ailelere operasyon öncesi, sırası ve
Tablo 3. Pediatri hemşirelerinin terapötik oyuna yönelik uygulama durumlarının dağıımı $(\mathrm{N}=126)$

\begin{tabular}{|c|c|c|}
\hline Uygulama Durumu & Sayı & $\%$ \\
\hline $\begin{array}{l}\text { Hastanede çocuğa terapötik oyun uygulatılma durumu } \\
\text { Evet } \\
\text { Hayır }\end{array}$ & $\begin{array}{l}98 \\
30 \\
\end{array}$ & $\begin{array}{l}77.7 \\
23.3 \\
\end{array}$ \\
\hline $\begin{array}{l}\text { Hemşirelerin terapötik oyun uyguladıkları durumlar } \\
\text { Tedaviye uyumlu olmayan çocuğa } \\
\text { Aşıı anksiyete ve korkusu olan çocuğa } \\
\text { Çocuğa invaziv girişim uygulamadan önce } \\
\text { illetişime kapalı çocuklarda } \\
\text { Oyun oynamayı seven çocuklarla } \\
\text { Herhangi bir işlem yapmıyorum }\end{array}$ & $\begin{array}{c}55 \\
82 \\
78 \\
38 \\
25 \\
2\end{array}$ & $\begin{array}{l}43.6 \\
72.5 \\
61.9 \\
30.1 \\
19.8 \\
1.5\end{array}$ \\
\hline $\begin{array}{l}\text { Çocuğun hastanede işlemlere uyumunu sağlamak için } \\
\text { yapılan hemşirelik uygulamaları } \\
\text { Terapötik oyun oynama } \\
\text { Aile üyelerinin çocuğun yanında olmasına izin verme } \\
\text { İşlemlerden korkmaması gerektiği söyleme } \\
\text { Herhangi bir işlem yapmama }\end{array}$ & $\begin{array}{c}84 \\
64 \\
94 \\
4\end{array}$ & $\begin{array}{l}66.0 \\
50.7 \\
90.2 \\
3.1\end{array}$ \\
\hline $\begin{array}{l}\text { Klinikte en çok uygulanan terapötik oyunlar } \\
\text { Kil ya da oyun hamuru } \\
\text { Tıbbi araçlarla oynama } \\
\text { Müzik dinletme } \\
3 \text { dilek testi } \\
\text { Resim çizdirme } \\
\text { Diğer }\end{array}$ & $\begin{array}{l}9 \\
61 \\
12 \\
20 \\
64 \\
21\end{array}$ & $\begin{array}{c}7.0 \\
48.4 \\
9.5 \\
15.8 \\
50.7 \\
16.6\end{array}$ \\
\hline $\begin{array}{l}\text { Hemşirelerin Terapotik oyun oynama sıklığı } \\
\text { Gerektiğinde her zaman uygularım } \\
\text { Bazen } \\
\text { Hiçbir zaman }\end{array}$ & $\begin{array}{c}6 \\
100 \\
20\end{array}$ & $\begin{array}{l}4.8 \\
79.4 \\
16.0\end{array}$ \\
\hline $\begin{array}{l}\text { Terapötik oyunu ara sıra uygulayan hemşirelerin } \\
\text { nedenleri } \\
\text { Zaman bulamama } \\
\text { Çok hasta olması } \\
\text { Ekip arkadaşlarının onayının olmaması } \\
\text { Malzemenin yetersiz olması } \\
\text { İş ortamında yeterli isteği kendinde bulamama }\end{array}$ & $\begin{array}{c}53 \\
75 \\
2 \\
18 \\
10\end{array}$ & $\begin{array}{c}42.0 \\
59.5 \\
1.5 \\
14.2 \\
7.9\end{array}$ \\
\hline
\end{tabular}

sonrası uygulamalarla ilgili rutin bilgiler verirken, deney grubu çocuk ve ailelerini operasyondan 1 hafta önce teropötik oyun girişimi için davet etmiştir. Deney grubu çocuklara intravenöz tedavi, anestezinin verilmesi, oksijen tedavisi ve yaşam bulgularını ölçülmesi tıbbi maket üzerinde gösterilmiş ve çocukların soru sormalarına, maketlere ve medikal cihazlara dokunmalarına ve oynamalarına izin verilmiştir. Araştırma sonucunda, teropötik oyun yöntemi ile operasyona hazırlanan çocukların ve ailelerinin anksiyete düzeyi, rutin bilgi verilen çocuklara göre önemli düzeyde düşük bulunmuştur (7).

Literatürde yer alan diğer çalışmalarda terapotik oyun yönteminin çocukların duygularını açıklama ve anksiyetesini azaltmaya etkisi belirlenmiştir (8-11). Terapötik tekniklerden resim çizdirmeye yönelik Beytut ve arkadaşlarının hastanede yatan 40 çocukla yaptığı çalışmada; çocukların çizdikleri resimlerde anksiyete, depresyon, düşük benlik saygısı gibi duygularını dışa vurmasına yardımcı olduğu ve kronik hastalı̆̆ı olan çocukların hastaneyi olumsuz çizdiği saptanmıştır (12). 
Literatürde çeşitli terapötik tekniklerin hastanede yatan çocuk üzerinde etkisine yönelik yapılan çalışmalar, bu çalışmaya katılan hemşirelerin terapötik oyunun türleri ve amacına yönelik bilgilerinin olduğunu göstermektedir.

Pediatri hemşireleri çocuğun işlemlere uyumunu sağlamak için yaptıkları uygulamaları; korkmaması gerektiği anlatma, terapötik oyun oynatma ve ailenin çocuğun yanında kalmasına izin verme şeklinde belirtmişlerdir. Çalışmaya katılan pediatri hemşirelerinin işlem öncesi çocuğa korkmaması gerektiğini söylemesinin etkili ve yaralı bir yöntem olduğu söylenemez. Bu tür bir yaklaşım çocuk ve hemşire arasında etkili iletişimi de engelleyebilmektedir. Bu yönden hemşirelerin bu tür bir yaklaşım içinde olmaları ve basmakalıp bir ifade kullanmaları düşündürücüdür. Bununla birlikte hemşirelerin yine büyük bir kısmının terapötik oyun yaklaşımı kullandıklarını belirtmeleri ve ebeveynlerin çocuğun yanında kalmasına izin vermeleri, çocuk ve ailesi için yararlı ve etkili bir yöntem olduğu söylenebilir. Karabudak ve ark 41 hekim ve 95 hemşire ile yaptığı "Girişimler Sırasında Aile Üyeleri Nerede Olmalı" konulu çaIışmalarında hemşireler ve hekimler daha çok damar yolu ve yara pansumanı gibi işlemlerde ailenin katılmasını istedikleri, LP ya da entübasyon gibi işlemlerde ailelerin çocuğun yanında kalmasına genellikle izin vermediklerini belirtmiştir. Aynı çalışmada hemşirelerin \%80'i ile hekimlerin \%58'i çocuğa duygusal ve manevi destek sağlamak için, hemşirelerin\%76'sı ile hekimlerin \%68.3'ü çocuğun korku ve anksiyetesini azaltmak için ebeveynlerin katılımına izin verdikleri belirlenmiştir (13). Bu çalışmada hemşirelerin ebeveyn katılımını sağlamaları terapötik oyun yöntemi olmasa da bütüncül bakım açısından önemli bir yaklaşım olduğu söylenebilir.

Araştırmaya katılan hemşireler terapötik oyunu kullanma sıklığını; gerektiğinde her zaman uygularım (\%4.8), bazen

\section{Kaynaklar}

1. Çavuşoğlu H. Çocuk Sağlığı Hemşireliği, 11. Baskı. Ankara: Sistem Ofset Basımevi; 2013. pp.67-87.

2. Cimete G, Kuğuluoğlu S, Dede Çınar N. Çocuk, hastalık ve hastane ortamı. İ̧̧inde: Conk Z, Başbakkal Z, Yılmaz B, Bolışık B. Pediatri Hemşireliği 1. Baskı, Ankara, Akademisyen Kitapevi; 2013. pp.133-141.

3. İnal S, Akgün M. Hastaneye yatan çocukta terapötik iletişim. Atatürk Üniv Hem YO Derg 2003;6:67-76.

4. Resmî Gazete. Hemşirelik Yönetmeliği. Sayı: 27910, 19.04.2011.

5. Landier W, Tse AM. Use of complementary and alternative medical interventions for the management of procedure-related pain, anxiety, and distress in pediatric oncology: an integrative review. J Pediatr Nur 2010;25:566-79. [CrossRef]

6. Ginsburg KR; the Committee on Communications, and the Committee on Psychosocial Aspects of Child and Family Health. The importance of play in promoting healthy child development and maintaining strong parent-child bonds. Pediatrics 2007;119:182-91. [CrossRef]

7. Li HCW, Lopez V. Effectiveness and appropriateness of therapeutic play intervention in preparing children for surgery: a randomized controlled trial study. J Spec Pediatrc Nurs 2008;13:63-73. [CrossRef]

8. Li HCW, Lopez V, Lee TLI. Effects of preoperative therapeutic play on outcomes of school-age children undergoing day surgery. Res Nurs Health 2007:30:320-32. [CrossRef] uygularım (\%79.4) ve hiç uygulamam (\%12.0) olarak saptandı. Hemşirelerinden terapötik oyunu bazen kullananlar ya da hiç kullanmayanlara bunun nedeni sorulduğunda, çok hasta oluyor (\%59.5) ve zaman bulamıyorum (\%42.0) şeklinde yanıtladıkları belirlendi. Hemşirelerin iş yükü ve iş yoğunluğunun fazla olması verilen hemşirelik bakımının kalitesini olumsuz olarak etkileyebilmektedir. Literatüde hemşirelerin iş yüklerinin fazla olması ve olumsuz çalışma şartları nedeni ile tükenmişlik düzeylerinin yüksek olduğu, bu durumun duygusal tükenme, duyarsızlaşmada artış ve iş motivasyonun olumsuz etkilenmesine neden olduğu belirtilmektedir $(14,15)$. Sayıl ve ark hemşire ve hekimlerin tükenmişlik düzeylerini araştırdığı bir çalışmada, hemşirelerin hastane içinde yoğun oldukları, hastalara yeterli zaman ayırmakta güçlük yaşadıkları, bu yüzden tükenmişlik hissettikleri belirlenmiş̧tir (15). Bu araştırmada hemşirelerin iş yoğunluğu nedeni ile çocuklara yeterli zaman ayıramaması, terapötik oyunu kullanma durumunu olumsuz etkileyebilmektedir.

\section{Sonuç ve öneriler}

Çalışmaya katılan hemşirelerin çoğunluğunun terapötik oyun çeşitlerini ve amacını bildikleri belirlendi. Pediatri hemşirelerinin uyguladıkları terapötik oyun çeşitlerinin daha çok tıbbi oyuncaklar, resim çizdirme, müzik dinletme yöntemleri olduğu saptandı.

Çalışmaya katılan hemşirelerin çok az bir bölümü terapötik oyunu gerektiğinde her zaman uyguladıklarını, çoğunluğu ise ara sıra uyguladıklarını belirtti. Terapötik oyunu ara sıra uygulayanlar iş yüklerinin fazla olması nedeni ile sürekli uygulayamadıklarını belirtti. Bu bulgular sonucunda hemşirelerin iş yoğunluğunun azaltılarak, terapötik oyun uygulamalarına olanak sağlanması ve terapötik oyun uygulamalarının pediatri kliniklerde yaygınlaştırılması önerilebilir.

9. Koukourikos K, Tzeha L, Pantelidou P, Tsaloglidou A. The importance of play during hospitalization of children. Mater Sociomed 2015;27:438-41. [CrossRef]

10. Li WHC, Chan SSC, Wong EML, Kwok MC, Lee ITL. Effect of therapeutic play on pre-and post-operative anxiety and emotional responses in Hong Kong Chinese children: a randomised controlled trial. Hong Kong Med J 2014;20:S36-9. Erişim: https://hub.hku.hk/bitstream/10722/214898/1/ Content.pdf?accept=1

11. Dündar SA. Pediatri kliniğindeki hemşire ve doktorların, müziğin klinikte kullanımı hakkındaki düşünceleri. ADÜTıp Fak Derg 2011;12:11-5. Erişim: https://dergipark.org.tr/download/article-file/681180

12. Şen-Beytut D, Bolışık B, Solak U, Seyfioğlu U. Çocuklarda hastaneye yatma etkilerinin projektif yöntem olan resim çizme yoluyla incelenmesi.. Maltepe Üniv Hemş Bilim ve Sanatı Derg 2009;2:35-44.

13. Karabudak SS, Ak B, Başbakkal Z. Girişimler sırasında aile üyeleri nerede olmalı? Özgün Araştırma. Türk Pediatr Arş 2010;45:53-60.

14. Kebapçı A, Akyolcu N. The Effects of the Work Environment on Nurse Burnout in Emergency Department. Türkiye Acil Tıp Derg 2011;11:59-67. [CrossRef]

15. Sayıl I, Haran S, Ölmez Ş, Özgüven HD. Ankara üniversite hastanelerinde çalışan doktor ve hemşirelerin tükenmişlik düzeyleri. Kriz Derg 1997:2:71-7. 